\title{
Research on the Automatic Production \& Equipment in Korea Japan and China
}

\author{
Run $\mathrm{Xu}$
}

Gyeongsang National University, Metallurgical Engineering Department, Gyeongsang nam-do, Chinju 52828, Korea

\author{
DOI: $10.36348 /$ sjet.2020.v05i11.003 \\ | Received: 18.10.2020 | Accepted: 04.11.2020 | Published: 06.11.2020 \\ *Corresponding author: Run Xu
}

\section{Abstract}

In this study the market of Japan, Korea and China is researched from actual. It is found that the automatic productions are popular in common. The automatic line and seller is developed direction in future. Meantime consumer of daily production is important in the future as well. The turns are Japan to China in this respect according to writer traveling. Korea is key ie. Middle position in these countries. So combining these three countries to common aim will be subject in future.

Keywords: Japan, korea and China, automatic productions, daily production, combining.

Copyright () 2020 The Author(s): This is an open-access article distributed under the terms of the Creative Commons Attribution 4.0 International License (CC BY-NC 4.0) which permits unrestricted use, distribution, and reproduction in any medium for non-commercial use provided the original author and source are credited.

\section{INTRODUCTION}

The market in Korea, Japan and China is investigated by residual there $[1,2]$. Because they are new developed countries in orient there are some difference detailed among them. I had been living in Korea for four years and seeing many matters there. It lies in between China and Japan so the key roles may be played through its development [3, 4]. Japan is called as western country due to its developed economic level from the nineteenth century to now. Since 2008 financial storm happened the world business and especially financial market is in critic still by now. How to resolve it has become kinds of specialist and common human talking issues. Economy overheat is the answer. So through travel for one week in Japan city some matters are seen there too. However China is still developing country but its economy capability will be beyond America to be No One nearly. With comparing this country it has been found that common point owned by them too [4]. In this paper detailing investigation would be proceeded between them and cause the members of economy sector attentions. Some related market investigation are found to be interesting and useful in the course of study so that the content are written here together to discuss for search, such as live necessity for detail. It is observed that automatic products and flow line are common trend in these countries currently and in the future. More and more these types of productions are dominantly in Japan. Korea and China in turns.

\section{DISCUSSIONS}

In South Korea, automatic equipment such as water purifier is distributed more, it is different from the traditional Chinese water purifier is to put mineral water into the machine is directly introduced through tap water. Although the Chinese industry now rises to separate the tap water directly, the number of people is relatively small. In South Korea, a water purifier like this is placed in every building of a typical university. It is more convenient to extract the water and provide it for people to quote. If you can put the mineral water into the pool of the last pass, it will greatly improve the quality of tap water, so that people drink refreshing and authentic. Since a bath does not require high-quality water, another pipe is connected to the shower so that it cannot be put in. This will solve the problem that Chinese people have difficulty drinking water. Because China's mineral water barrels are too many, too messy, the streets are full of water delivery. This is not good for traffic order. The citizens all hope for a quiet and leisure community. Although it is better now, there are still water delivery people. This is a consequence of having to employ surplus people to get them to work. In this way, automation equipment cannot be utilized and used, which is the reason for the low level of national modernization. Although such things as bullet trains and buildings are relatively developed, their maintenance is not in place and they are allowed to develop freely. Such as the motor car used for more than a year, the body of serious aging, white paint into gray, no one tube. Want to order to spray paint long ago 
Run Xu; Saudi J Eng Technol, Nov, 2020; 5(11): 416-418

in Korea. High-speed trains are named after the environment. Factories in South Korea produce more gasoline and chemicals, including a gasoline refining plant, a chemical production base there, a modern oil plant there. In order to prevent leakage of storage tanks and pipelines, chemical tests should be carried out regularly to assess their service life. For this purpose, a comprehensive research institute and testing company are specialized in the technical identification of welding sites. Because these chemical plants need to make technical preparations in advance in case of serious accidents, we also went to the relevant sites to participate in the technical appraisal work for many times. This was done by a company called Meetech, part of the Korea mechanical research institute in Changwon. There are a number of engineering consultancies in Korea that specialize in consulting on company technology and equipment. Our main reproducing metal material aspects of the organization, the crack part with copy copy after buffing, and corrosion are extracted, and then back for identification, to determine the composition and service life. Sometimes twenty copies have to be made at a time because of too many cracks. And the factory is paid by the travel fee plus the number of copies. This is also the chemical products automatic production line equipment verification. South Korea is a country full of industrial factories. As a technical engineer, there are many opportunities to display their talents and give back to the society. Their consulting firm has many engineers working as agents for large and medium-sized Chinese companies. Their technology is first-class and their service is first-class. It is wise to apply the Korean experience to Chinese factories. Chinese factories have been producing low and middle level technological productions usually. For instance the common production: auto vehicle genre. However they can even address production line equipment, such as product function lines that are less heavy but have more complex mechanical functions. Knowledge intensive, it allows them to organize views and manufacturing, as long as they are paid. Chinese engineers have a hard time understanding, let alone making, these advanced devices. Since we mainly learned manufacturing equipment rather than functional transport aircraft, we should learn more about the advanced technologies of the Oriental countries, so as to solve the complex and detailed problems encountered in practice, which is also a method of discussion. If we also manufacture specific functional product lines, some people will be assigned to study this topic. Will it be too refined and technical conflicts with Korea and Japan? That are the problems we are facing. More people is our advantage, but not enough refinement, can be completed in advance it is also a problem. But we should not be so ignorant that we lose our ability to overcome difficulties. Follow up slowly and don't fall behind. Seriously organize technical personnel to visit and inquire, encounter these problems can quickly solve the relevant core content.
We will actively explore relevant issues and make efforts to resolve them as soon as possible.

In Japan vending machines are much. One lies in subway station that has more than several ten types cigarettes to sell; the other lies in beside cross street that has more than ten types beers to sell. Buyer needs to put coins and money into slot then chooses the button of wanting and takes it from machine. It is very convenient. However it has many kinds of production and the price is low to fit to civilians simply. It has been human rare but it has been popular since the subway. It doesn't adopt many person to use commonly however civilians can buy many of them not to be confined. So that though humans amount has not much it could resolve rudiment production. It can make one to spare leisure time quickly and quantitatively. Because it could work continuously 24 hours it can be used in deep night and morning early. Because it has been working time it can satisfy civilians very much. The utilized rate will attend summit in the morning early. Since work time there is not standing position almost. At the time it is rare so it explains Japanese is main in work and then the leisure. It does not like chinese big city crowded all the time.at the Japan station the persons is crowded as well who are almost looking for their occupations. In China the famous American Starbucks is popular as a coffee shop where many businessmen are talking about prevailed business topic. That symbols China has been becoming a international important member to wield its role in the world more and more dominantly. Currently China is about to be No. 1 economic country instead of America so more and more significant determination on world economy will be done and affected by us. China has been become world center in manufacture and international trade due to its population and GDP (gross domestic product) of 1.4 billion.

The Japanese will be more indignant than Chinese job hunters and endure toleration much harder. Their products are sophisticated since they are main in working. Anything could be trivial to compare with work. They indulge at leisure time so that the service is rather complicated. In Japan a lot of unemployment's person has been looking for vacant in the afternoon opposed to its prospering. Japan is neighborhood to Korea so that all the skills are passed by it. For example Korean engineer technology mentioned above. Some of technology has been derived from Japan which style includes automatic line such as flow and dispersion machine line. I received once in Korean company and found it is difficult to understand its each part drawing because it is too sophisticated and detailed. After seeing first drawing others is impossible to continue. The total page is more than 10 . We sent it to Korean consulting company to solve in the end. They had engineer to catch and manufacture the whole automatic line. Maybe it is designed by Japanese engineer. It is hard to understand for us at all. This is the device of Dahan Powder in development zone of Yantai. They have 
Japanese automatic flow line to assemble in new production line. My staff and I both have not ability to catch the designing draw so we get rid of it. In fact Japan and Korea have connection in automatic flow line device. Japanese engineer designs the equipment for Korean factory indeed and they will be responsible for manufacturing and assembly on the whole. Our Chinese engineer knows few about the automatic line manufacturing just like Korean. Only the basic functions can we learn after it is assembled then. We ought to promote our ability to solve problems about its some functions. Once some design issues happened should we not have method to solve it at all. So we ought to learn more about Japanese manufacture technology. We can design and manufacture automatic line by ourselves not dependent only on Japan. We need to look for status on the other hand. That the GDP exceeds them is the oughting way for us. The current situation has needed some time in future. We must exploit them to get rid of avoiding them. As to the advanced technology we need to import it and digest to exceed them as early as possible. It can make sure that our profits will not be harmed and realize advanced and leading position. In order to research and manufacture advanced and functional machine we is to become the advanced machine maker in the future.

\section{CONCLUSIONS}

In China it is chasing Japan and Korea with industrious production line. Automatic products are utilized popularly more and more in special mechanical Assembly line. Japan has been selling products automatic seller to advertise abroad by many advertisements. Korea is following China to fight high price consumer of daily production. Japan's key role is wielding more and more currently. In order to research and manufacture advanced and functional machine we is to become the advanced machine maker in the future.

\section{REFERENCES}

1. John, J. Wild, Ken, W Shaw., Barbara, C. (2015). Account Principle [M]. China Renmin university press, 21st Edition, 2015: 127

2. Compilation group of economics textbook series. (2013). Microeconomics [M], economic science press, 15

3. Jing, F., Zeng, F. (2016). Marketing research [M]. Higher education press, 105

4. Xie, B. (2009). Financial Market [M]. Peking University press, 7 24

\section{Brief Biography}

$\mathrm{XU}$ Run is a PHD in school of Material Engineering Department in Geongsang National University. His research direction is material of metal cutting\& management and business administration etc. Xurun1206@163.com 